\title{
Carrier Based Sinusoidal Pulse Width Modulation Control Strategy for Three Phase Nine Level Diode Clamped Multilevel Inverter and Hybrid Inverter with Reduced Components
}

\author{
${ }^{1}$ N.Susheela, ${ }^{2}$ P.Satish Kumar \\ ${ }^{1,2}$ Assistant Professor, Department of Electrical Engineering, University College of Engineering (A), Osmania University \\ Hyderabad, Telangana, India
}

Received: $10^{\text {th }}$ Feb 2018, Accepted: $2^{\text {th }}$ March 2018, Published: $30^{\text {th }}$ April 2018

\begin{abstract}
The most widely used pulse width modulation scheme for diode clamped multilevel inverters (DCMLI) is the multicarrier based sinusoidal pulse width modulation. Though this technique is simpler and more flexible for implementation, the maximum peak of the fundamental component in the output voltage is limited to fifty percent of the voltage in the DC link. So, the hybrid multilevel inverter is proposed with superior features such as achieving more fundamental output voltage, requires fewer carrier signals, less components and gate drive circuits. Therefore, the overall cost and complexity of the hybrid inverter are greatly reduced particularly for higher inverter output voltage levels. A comparative analysis of three phase diode clamped multilevel inverter and hybrid multilevel inverter is presented in this paper using carrier based sinusoidal pulse width modulation technique. The performance of both the inverters are reported based on alternate phase opposition disposition (APOD) sinusoidal pulse width modulation (SPWM) strategy. Simulation is performed for three phase nine level diode clamped multilevel inverter and hybrid multilevel inverter using MATLAB/Simulink for induction motor load and the total harmonic distortion is evaluated at different load torques.
\end{abstract}

Keywords: Diode clamped multilevel inverter; Pulse width modulation; Hybrid inverter; Total harmonic distortion; Induction motor

\section{Introduction}

The multilevel inverters (MLI) have been attracting in recent decade due to its several benefits [1]-[5]. The commutation of the components aaggregate the multiple dc sources to gain output with higher levels. A 3-level boost converter which is connected to the inner capacitors of a 5-level diode clamped multilevel inverter (DCMLI) along with extra balancing circuit at the outer capacitors is presented using capacitor voltage balancing [6]. The carrier based multilevel PWM methods are reported to optimize or balance the utilization of the switches that are used in MLI [7]. A simple neutral point (NP) voltage regulator for a 3 level DCMLI is reported where a multiple carrier sine triangle modulator in conjunction with a closed loop controller for neutral point regulation [8]. The 3-phase front end bidirectional 5-level rectifier and rear end 5-level inverter are focused based on multiple pole multilevel DCMLI approach to reduce the semiconductor [9].

The PWM technique is demonstrated to improve performance of a 3-phase DCMLI for 3 and 4 levels which can be extended to any levels [10]. The various hybrid techniques and its comparison is made for different applications to reduce the switches [11]. A hybrid MLI that is symmetrical is focused using modulation methods for single and three phase systems which is based on a 3-level switching cell and does not require capacitors nor diodes [12]. A combination of flying capacitor and cascaded inverters is presented which provides higher output levels with lower components with less losses [13]. An asymmetrical multi-pulse connection of uncontrolled rectifiers with hybrid MLI is elaborated to improve the input harmonic performance of adjustable-speed drives [14]. An inverter with hybrid modulation method is presented that incorporates stepped synthesis. The full bridge rectifier for single phase is discussed to analyze the performance of the MLI [15]. The NP potential regulator is discussed to determine the magnitude of variable offset voltage based upon different parameters [16]. A different topology is introduced for single phase 7 level inverter using phase disposition method for RL load to improve the performance of the inverter by compensating the disadvantages of classical MLI such as higher components, complex PWM and voltage-balancing problem [17].

As reported in the literature, the DCMLI need greater number of components. This paper presents an implementation of a three phase 9 level hybrid MLI inverter using alternate phase opposition disposition (APOD) carrier based sinusoidal pulse width modulation technique (SPWM). In classical MLI, the switches are combined to produce a high-frequency waveform in positive and negative polarities. Whereas in the hybrid multilevel inverter, all the switches need not be utilized for producing bipolar levels. This topology presented in this paper combines the level generation part and polarity generation part to generate the required nine level output.

\section{Sinusoidal Pulse WidTh Modulation}

The PWM method is shown in Fig. 1. The inverter output voltage is $\mathrm{V}_{\mathrm{dc}} / 2$ when $\mathrm{V}_{\text {control }}>\mathrm{V}_{\text {tri and }}-\mathrm{V}_{\mathrm{dc} / 2 \text { when }} \mathrm{V}_{\text {control }}$ $<\mathrm{V}_{\text {tri }}$ as expressed in (1) and (2). 


$$
\begin{aligned}
V_{A O}= & \frac{V_{d c}}{2} \\
& V_{A O}=-\frac{V_{d c}}{2}
\end{aligned}
$$

PWM frequency is the same as the frequency of $\mathrm{V}_{\text {tri. }}$. Amplitude is controlled by the peak value of $\mathrm{V}_{\text {control }}$ and Fundamental frequency is controlled by the frequency of $\mathrm{V}_{\text {control. }}$.

Modulation index (m) is given by: $m=\frac{V_{\text {control }}}{V_{\text {tri }}}$
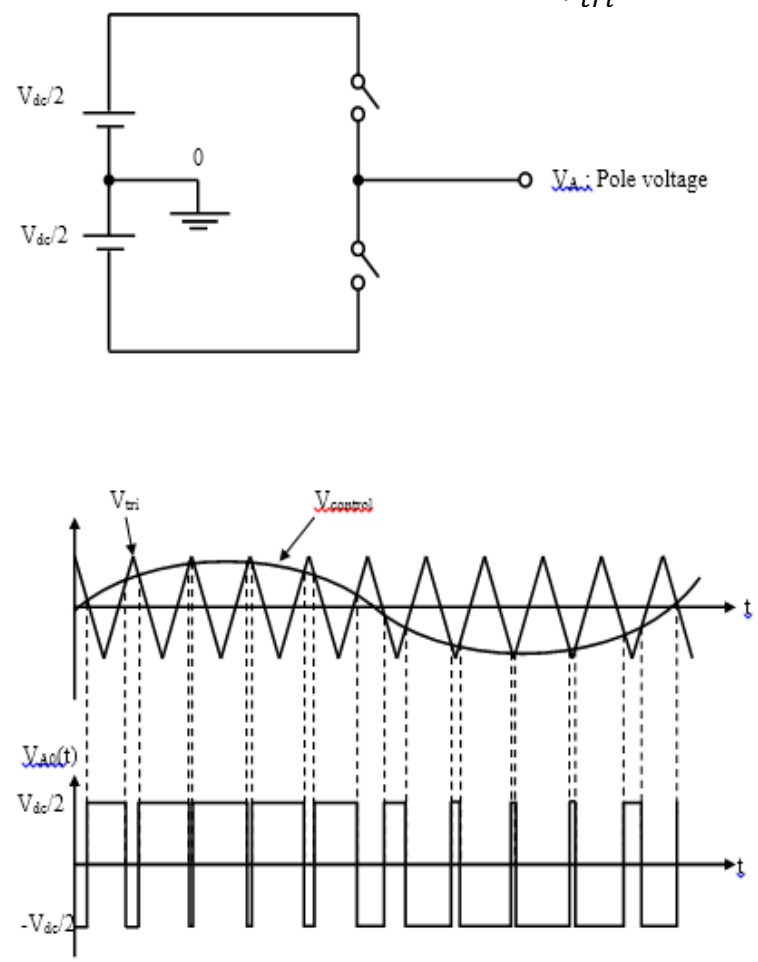

Fig.1. Sinusoidal PWM

\section{Nine LeVel Diode Clamped MUlTilevel InVERTER}

The concept of this inverter is to use diodes to limit the power devices voltage stress. The diode is used as the clamping device to clamp the dc bus voltage so as to achieve steps in the output voltage. The switches in one phase of a nine-level diode clamped inverter are arranged into 8 pairs i.e., (S1, S9), (S2, S10), (S3, S11), (S4, S12), (S5, S13), (S6, S14), (S7, $\mathrm{S} 15)$ and (S8, S16). When one switch of the pair is turned ON, the other switch of the same pair must be OFF. Each switch pair works in complimentary mode and the diodes are used to provide access to mid-point voltage. At any point of time 8 switches are triggered to achieve desired level. The $\mathrm{DC}$ bus voltage is split into nine voltage levels by using eight series connection of DC capacitors $\mathrm{C} 1$ to $\mathrm{C} 8$. For a DC bus voltage $\mathrm{V}_{\mathrm{dc}}$, the voltage across each capacitor is $\mathrm{V}_{\mathrm{dc}} / 8$ and voltage stress on each device is limited to $\mathrm{V}_{\mathrm{dc}} / 8$ through clamping diodes. The middle point of the ten capacitors ' $N$ ' can be defined as the neutral point. In order to produce nine levels by sinusoidal pulse width modulation, eight saw-tooth waveforms for carrier and a sinusoidal reference signal for modulator are required for nine level diode clamped inverter.

\section{NINE LEVEL HYBRID MLI}

The schematic of 9 level hybrid MLI is shown in Fig.2 for one phase. It requires 12 switches and four isolated sources which are equally rated. Level generation part of the 9 level hybrid inverter generates 5 levels and later these voltage levels will be inverted by using polarity generation part when the voltage polarity requires to be changed for negative polarity. For the supply voltage $\mathrm{V}_{\mathrm{dc}}$, the 5 levels which are generated by level generation part are $0, V_{\mathrm{dc}} / 4, \mathrm{~V}_{\mathrm{dc}} / 2,3 \mathrm{~V}_{\mathrm{dc}} / 4$, $\mathrm{V}_{\mathrm{dc}}$. Later by using the polarity generation part, positive levels are converted into negative polarity (i.e., $\mathrm{V}_{\mathrm{dc}} / 4, \mathrm{~V}_{\mathrm{dc}} / 2$, $3 \mathrm{~V}_{\mathrm{dc}} / 4, \mathrm{~V}_{\mathrm{dc}}$ are converted to $\left.-\mathrm{V}_{\mathrm{dc}} / 4,-\mathrm{V}_{\mathrm{dc}} / 2,-3 \mathrm{~V}_{\mathrm{dc}} / 4,-\mathrm{V}_{\mathrm{dc}}\right)$ as per the requirement of output polarity. Thus the nine levels are generated using this method.

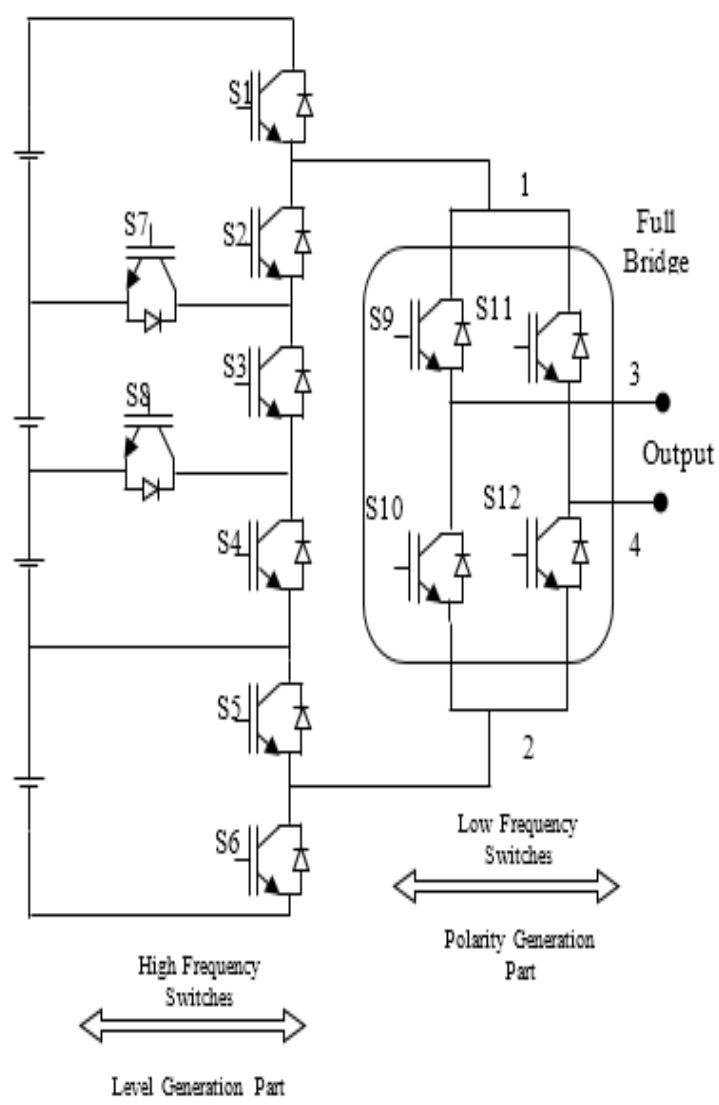

Fig. 2 Schematic of nine level hybrid inverter for one phase

The required positive 5 levels are produced by the highswitching-frequency components of the inverter. Different 
switching modes in generating the required levels for a 9 level hybrid inverter are shown in Table 2 with 8 patterns.

TABLE: SWITCHING STATES OF NINE LEVEL HYBRID INVERTER

\begin{tabular}{|c|c|c|c|c|c|}
\hline Modes & $\mathbf{0}$ & $\mathbf{1}$ & $\mathbf{2}$ & $\mathbf{3}$ & $\mathbf{4}$ \\
\hline 1 & $\begin{array}{r}\text { S2, S3, } \\
\text { S4, S5 }\end{array}$ & $\begin{array}{r}\text { S2, S3, } \\
\text { S4, S6 }\end{array}$ & $\begin{array}{c}\text { S2, S3, } \\
\text { S8, S6 }\end{array}$ & $\begin{array}{c}\text { S2, S7, } \\
\text { S6 }\end{array}$ & S1, S6 \\
\hline 2 & & $\begin{array}{r}\text { S2, S3, } \\
\text { S8, S5 }\end{array}$ & $\begin{array}{c}\text { S2, S7, } \\
\text { S5 }\end{array}$ & S1, S5 & \\
\hline
\end{tabular}

\section{SIMULATION AND RESUlTS ANALYSIS}

The simulation and results are discussed in this section for three phase 9 level DCMLI and hybrid MLI using APOD technique. The APOD carrier based SPWM method is performed for both the three phase inverters. The specifications considered are nominal power $=10 \mathrm{hp}$, rms voltage $=400 \mathrm{~V}$, poles $=4$, frequency $=50 \mathrm{~Hz}$, speed $=1500 \mathrm{rpm}$, $\mathrm{R}_{\mathrm{s}}=0.7384 \Omega, \mathrm{R}_{\mathrm{r}}{ }^{\prime}=0.7402 \Omega, \mathrm{L}_{\mathrm{ls}}=3.045 \mathrm{mH}, \mathrm{L}_{\mathrm{lr}}{ }^{\prime}=3.045 \mathrm{mH}$, $\mathrm{L}_{\mathrm{m}}=0.1241 \mathrm{H}, \mathrm{J}=0.07 \mathrm{kgm} 2$. The waveforms of three phase 9level DCMLI are shown from fig. 3 to fig. 6 for IM load. The results of three phase 9-level hybrid inverter are presented from fig. 7 to fig.10. The comparative analysis of both the inverters is performed and the speed and torque response, stator currents and voltage spectrum are depicted from Fig.11 to Fig.16.

\section{Three Phase Nine level DCMLI using APOD method}

The carrier arrangement for APOD technique in three phase nine level DCMLI is shown in Fig.3. The gating pulses in one phase of nine level diode clamped inverter is shown in fig.4 for S1 to S8 switches and Fig.5 for S9 to S16 switches.

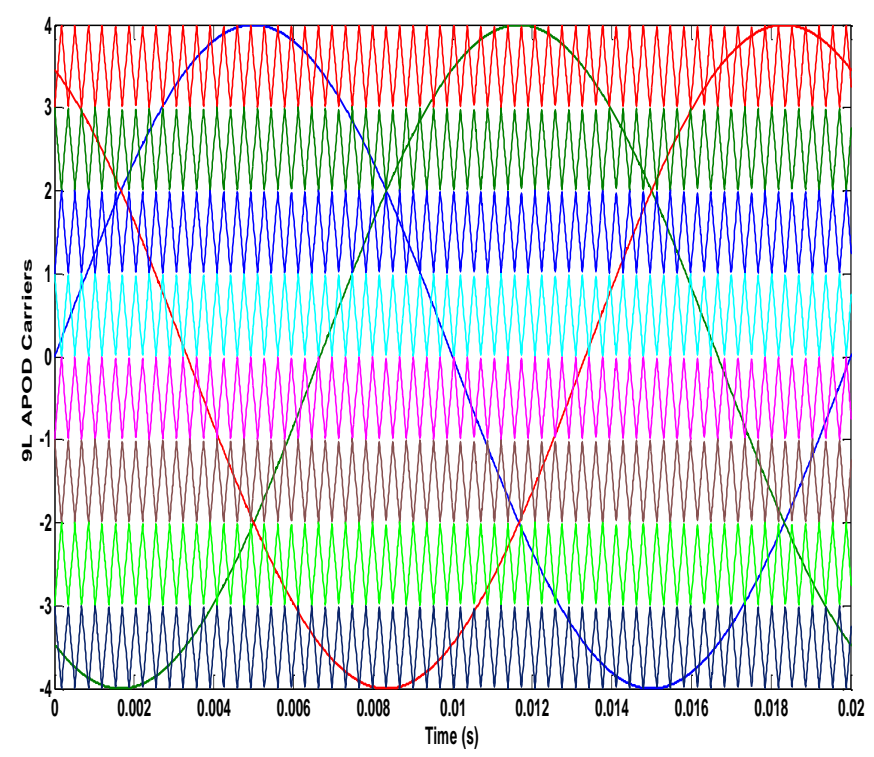

Fig.3. Carriers for nine level DCMLI using APOD method

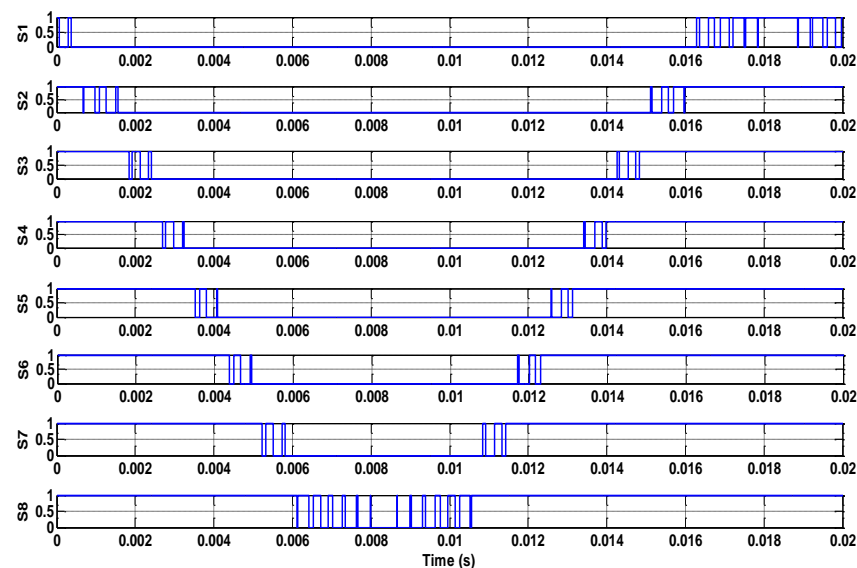

Fig. 4 Gating pulses in nine level DCMLI for switches S1 to S8 using APOD

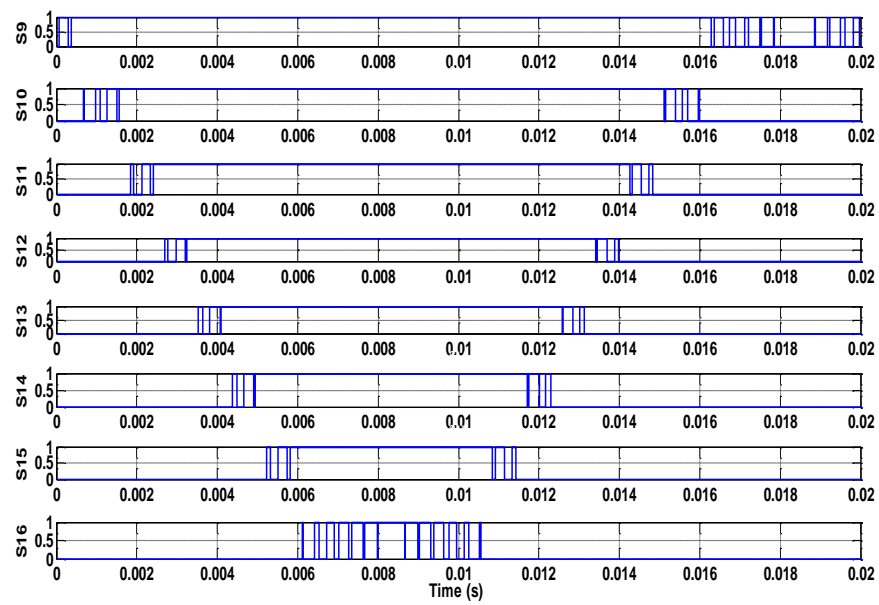

Fig. 5 Gating pulses for nine level DCMLI for switches S9 to $\mathrm{S16}$

The three phase voltages and currents of three phase nine level DCMLI are represented in Fig.6.

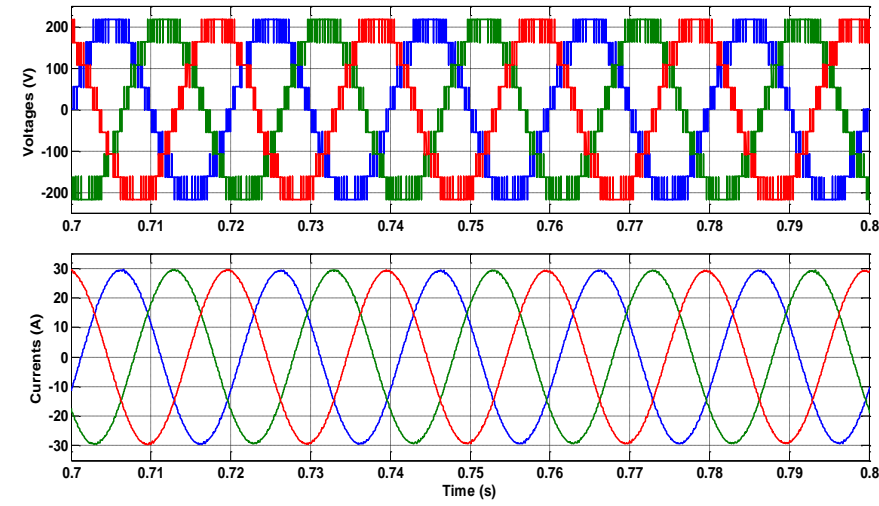

Fig. 6 Three phase voltages and currents of nine DCMLI fed IM 


\section{Three phase nine level hybrid MLI using APOD}

The APOD SPWM technique is implemented for three phase 9 level hybrid MLI. The carrier arrangement of APOD strategy can be seen in Fig.7 below. In order to produce nine levels by SPWM, four saw-tooth waveforms for carrier and three sinusoidal reference signal for modulator are needed.

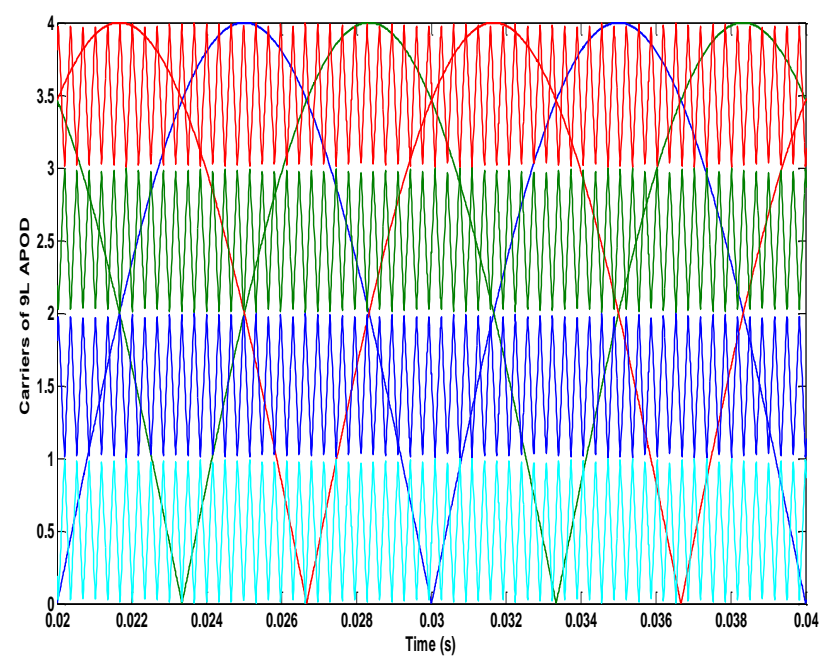

Fig. 7 Carriers for three phase nine level hybrid inverter using APOD

The phase voltages of level generation part and polarity generation part of nine level hybrid inverter using APOD method are shown in Fig. 8 and Fig.9. The current waveforms are presented in fig. 10 for three phase 9 level hybrid MLI fed IM.
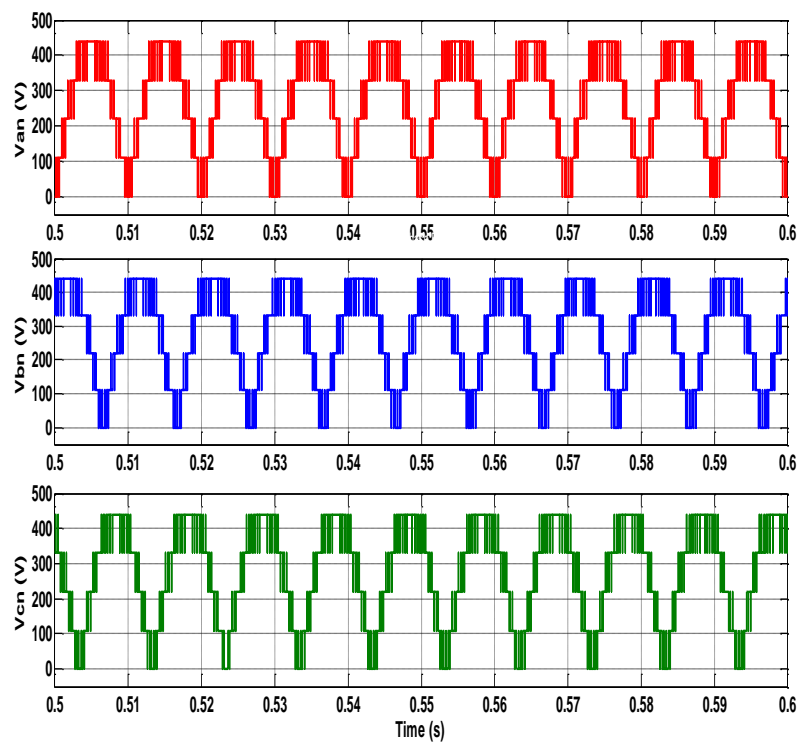

Fig. 8 Phase voltages of level generation part of nine level hybrid inverter
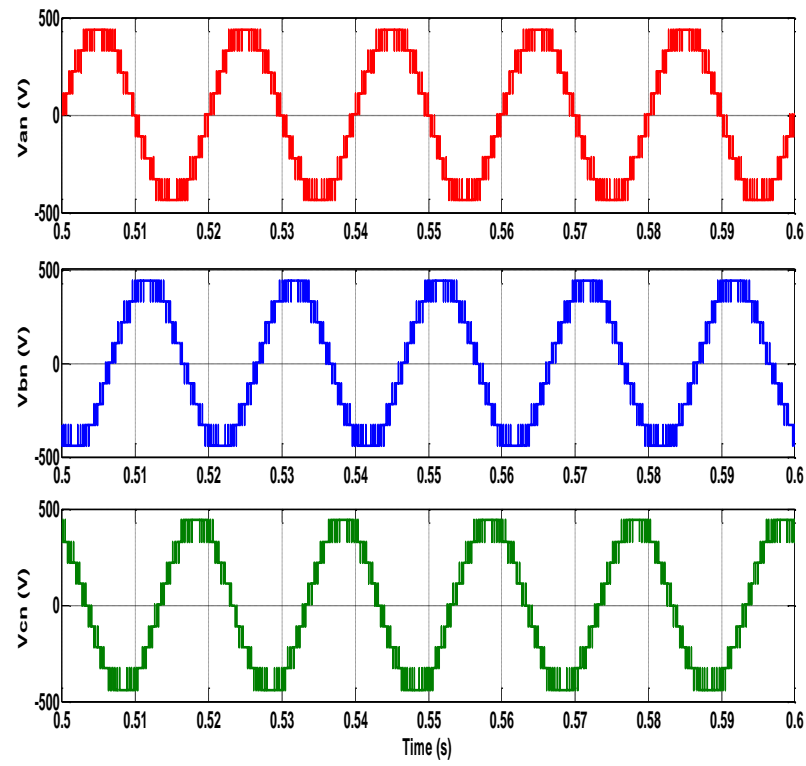

Fig. 9 Voltages of polarity generation in nine level hybrid inverter

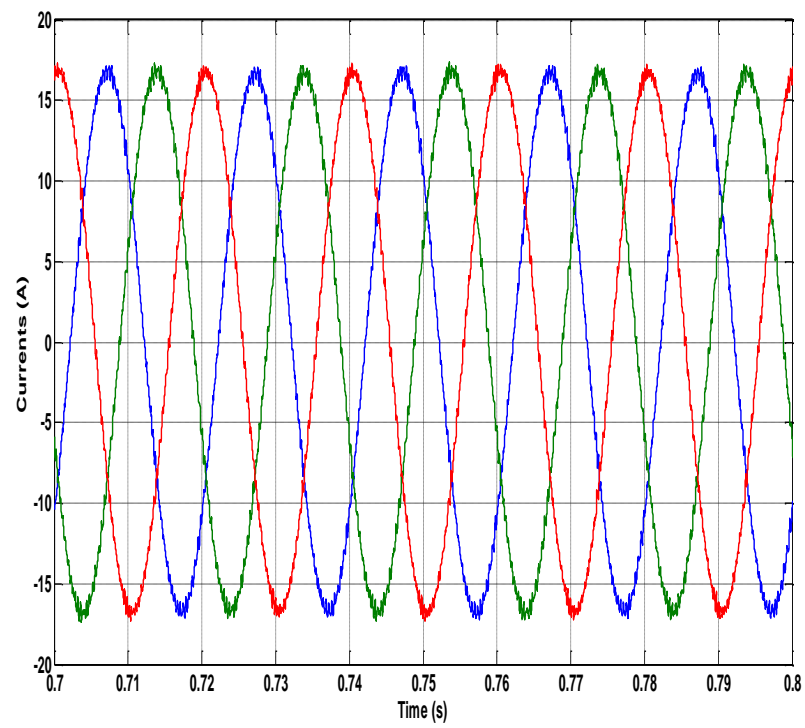

Fig. 10 Current waveforms of three phase nine level hybrid inverter

Comparison of Nine level diode clamped MLI and hybrid inverter using APOD technique

Fig.11 and fig.12 demonstrates the response of rotor speed and electromagnetic torque for three phase nine level diode clamped MLI and hybrid MLI fed induction motor using APOD method. Whereas, the stator currents of DCMLI and hybrid MLI fed IM are presented in Fig.13 and Fig.14. The FFT analysis carried out for nine level DCMLI and hybrid MLI are shown in fig. 15 and fig.16 using APOD method. 

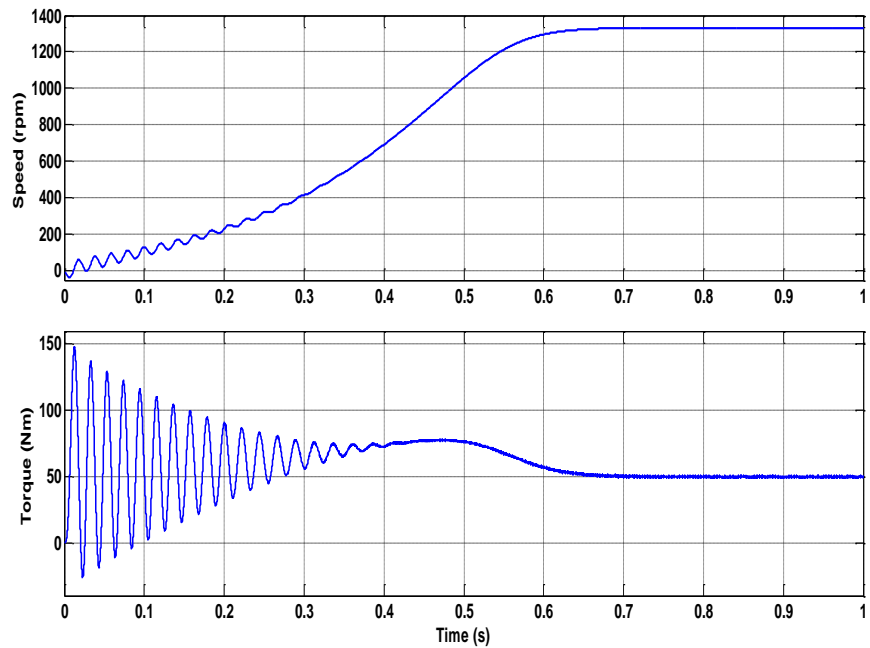

Fig. 11 Speed and torque response of nine level DCMLI using APOD method
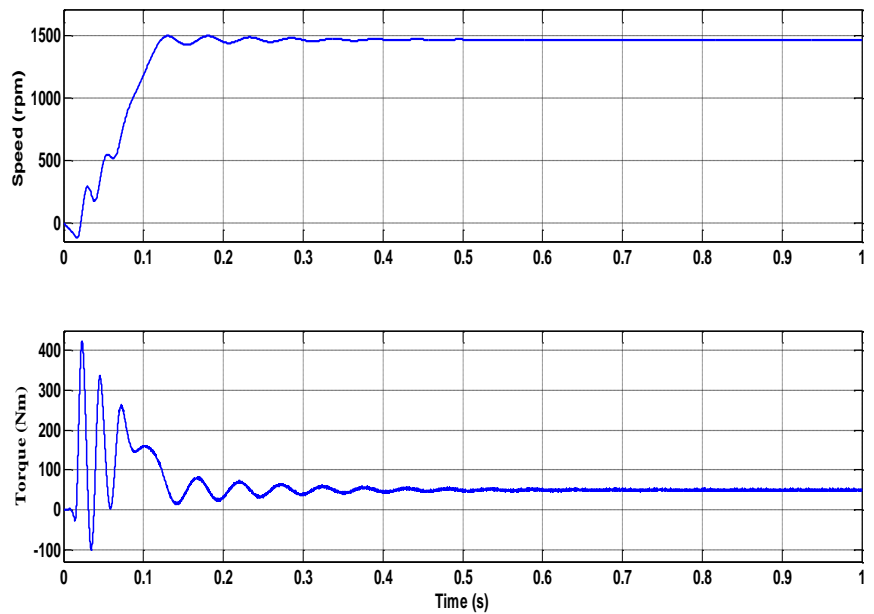

Fig. 12 Speed and torque response of nine level hybrid MLI using APOD

From the results of speed torque responses, it is observed that the speed of nine level DCMLI and hybrid MLI fed IM are settled at 0.67 seconds and 0.24 seconds. Whereas the torque response has become constant at 0.62 seconds for 9 level DCMLI fed IM and 0.5 seconds for 9 level hybrid MLI fed IM.

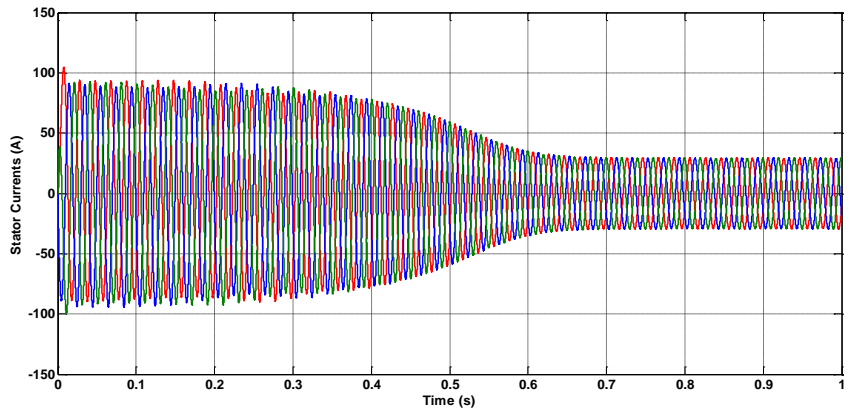

Fig. 13 Stator Currents of nine level DCMLI fed IM using APOD

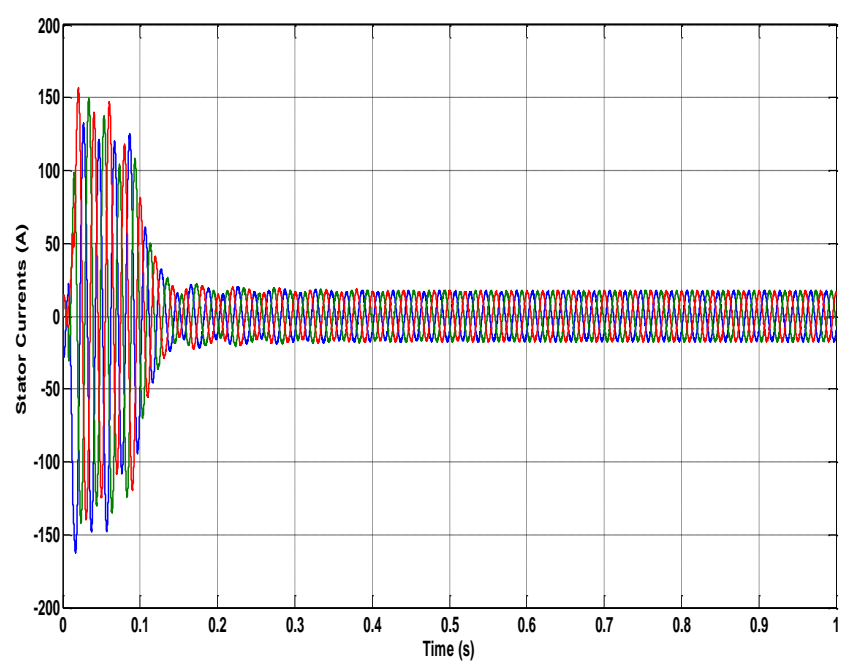

Fig. 14 Stator Currents of nine level hybrid MLI fed IM using APOD

The stator currents in 9 level DCMLI fed IM are observed to be nearly sinusoidal after 0.65 seconds whereas 0.29 seconds in nine level hybrid MLI fed IM using APOD technique.

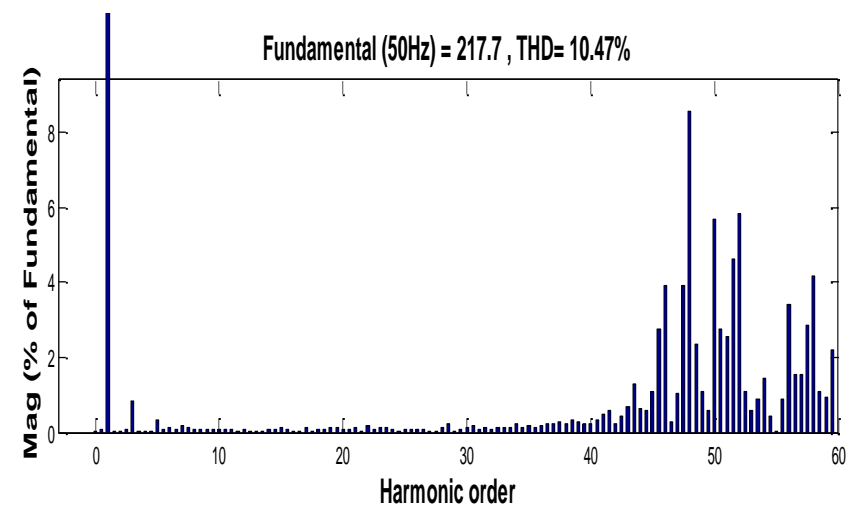

Fig. 15 Voltage spectrum of nine level DCMLI fed IM using APOD method 


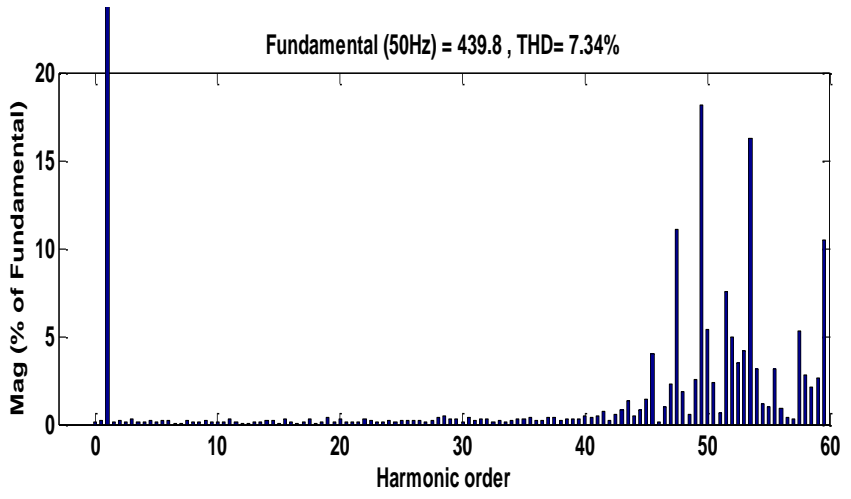

Fig. 16 Voltage spectrum of nine level hybrid MLI fed IM using APOD

The voltage THD of nine level hybrid MLI is reduced by 3.13 $\%$ compared to nine level DCMLI using APOD method.

The voltage THD in case of DCMLI and hybrid MLI is shown in Table II at various loads and Table III summarizes the fundamental output voltage obtained.

TABLE I. VOLTAGE THD (\%)

\begin{tabular}{|c|c|c|c|}
\hline $\begin{array}{c}\text { Output } \\
\text { voltage } \\
\text { level }\end{array}$ & $\begin{array}{c}\text { Load } \\
\text { Torque }\end{array}$ & $\begin{array}{c}\text { Diode } \\
\text { Clamped } \\
\text { MLI }\end{array}$ & $\begin{array}{c}\text { Hybrid } \\
\text { MLI }\end{array}$ \\
\hline \multirow{2}{*}{$\begin{array}{c}\text { Nine } \\
\text { level }\end{array}$} & No Load & 10.42 & 7.07 \\
\cline { 2 - 4 } & Half Load & 10.54 & 7.21 \\
\cline { 2 - 4 } & Full Load & 10.47 & 7.34 \\
\hline
\end{tabular}

TABLE II. COMPARISON

\begin{tabular}{|c|c|c|}
\hline \multirow{2}{*}{ Level } & \multicolumn{2}{|c|}{$\begin{array}{c}\text { Fundamental Output } \\
\text { Voltage }\end{array}$} \\
\cline { 2 - 3 } & $\begin{array}{c}\text { Diode } \\
\text { Clamped } \\
\text { Inverter }\end{array}$ & $\begin{array}{c}\text { Hybrid } \\
\text { Inverter }\end{array}$ \\
\hline Nine level & 217.7 & 439.8 \\
\hline
\end{tabular}

\section{CONCLUSION}

This paper focuses on comparative analysis of two multilevel inverter topologies. One is the diode clamped multilevel inverter and the other is hybrid multilevel inverter with reduced number of components. The FFT analysis is carried out for these inverters using APOD pulse width modulation technique for nine level. The results of voltage, current, speed and torque response, stator currents and THD of voltage and current of diode clamped and hybrid inverter fed induction motor are analyzed, based on which a comparison between the diode clamped multilevel inverter and hybrid multilevel inverter is provided. The hybrid multilevel inverter has some unique features that have promoted its application in the MV drives, whereas the practical use of the diode clamped multilevel inverter seems limited due to the use of a large number of components, poor voltage THD and complex control scheme.

\section{Reference}

[1] Akira nabae, Isao Takahashi, and Hirofumi Akagi, "A New Neutral-point-Clamped PWM Inverter", IEEE Trans. Indu apps.,vol.1A-17, no.5, pp.518-523, sept/oct.1981.

[2] Jih-Sheng Lai and Fang Zheng Peng, "Multilevel Converters-A New breed of Power Converters," IEEE Trans. Indu apps.,vol.32, no.3, pp.509-517, may/june 1996.

[3] Xiaoming Yuan and Ivo Barbi, "Fndamentals of New Diode Clamping Multilevel Inverter," IEEE trans. Power .,vol.15,no.4,pp.711-718, july 2000.

[4] Jose Rodriguez, Jih-Sheng Lai, and Fang Zheng peng, "Multilevel Inverters: A Survey of Topologies, Controls, and Applications," IEEE trans. Indu ele., vol.49, no.4, pp.724-738, August 2002.

[5] Mohan M. Renge, and Hiralal M.Suryawanshi, "Fivelevel Diode Clamped Inverter to Eliminate Common Mode Voltage and Reduce dv/dt in medium Volatge Rating Induction Motor Drives," IEEE trans. Power ele., vol.23, no.4, pp.1598-1607,July 2008.

[6] Rosmadi Abdullah, Nasrudin Abd. Rahim, Siti Rohani Sheikh Raihan, and Abu Zaharin Ahmad, "Five-Level Diode-Clamped Inverter With Three-Level Boost Converter," IEEE trans. Indu ele., vol.61, no.10, pp.5155-5163, Oct.2014.

[7] Leon M. Tolbert, and Thomas G. Habetler, "Novel Multilevel Inverter Carrier-Based PWM Method," IEEE trans. Indu apps., vol.35, no.5, pp.1098-1106, Sept/Oct.1999.

[8] Ashish Bendre, Giri Venkataraman, Don Rosene, and Vijay Srinivasan, "Modeling and Design of a NeutralPoint Voltage Regulator for a Three-Level Diode Clamped Inveter Using Multiple-Carrier Modulation," IEEE trans. Indu ele., vol.53, no.3, pp.718-726, June 2006.

[9] Gabriel H. P. Ooi, Ali I. Maswood, and Ziyou Lim, "Five-Level Multiple-Pole PWM AC-AC Converters with reduced Component Count," IEEE trans. Indu ele., vol.62, no.8, pp.4739-4748, August 2015.

[10] Ramkrishan Maheshwari, Sergio Busquets-Monge, and Joan Nicolas-Apruzzese, "A Novel Approach to Generate Effective Carrier-Based Pulse width Modulation Strategies for Diode-Clamped Multilevel DC-AC Converters," IEEE trans. Indu ele., vol.63, no.11, pp.7243-7252, Nov 2016.

[11] Cassiano Rech, and Jose Renes pinherio, "Hybrid Multilevel Converters: Unified Analysis and Design Considerations," IEEE trans. Indu ele., vol.54, no.2, pp.1092-1104, April 2007.

[12] Domingo A. Ruiz-Caballero, Reynaldo M. RamosAstudillo, Samir Ahmad Mussa, and Marcelo Lobo Heldwein, "Symmetrical Hybrid Multilevel DC-AC Converters with Reduced Number of Insulated DC Supplies," IEEE trans. Indu ele., vol.57, no.7, pp.23072314, July 2010 
[13] Pablo Lezana, and Roberto Aceiton, "Hybrid Multicell Converter: Topology and Modulation," IEEE trans. Indu ele., vol.58, no.9, pp.3938-3945, Sept 2011.

[14] Cassiano Rech, and Jose Renes Pinheiro, "Impact of Hybrid Multilevel Modulation Strategies on Input and Output Harmonic Performances," IEEE trans. Power elec., vol.22, no.3, pp.967-976, May 2007.

[15] Madhav D. Manjrekar, Peter K. Steimer, and Thomas A. Lipo, "Hybrid Multilevel Power Conversion System: A Copmpetitive Solution for High-Power Applications," IEEE trans. Ind elec., vol.36, no.3, pp.834-841, May/June 2000.

[16] Pradyumn Chaturvedi, Shailendra Jain, and Pramod Agarwal, "Carrier-Based Neutral Point Potential Regulator with Reduced Switching Losses for ThreeLevel Diode-Clamped Inverter," IEEE trans. Ind elec., vol.61, no.2, pp.613-624, Feb 2014.

[17] Ehsan Najafi and Adul Halim Mohamed, "Design and Implementation of a New Multilevel Inverter Topology," IEEE trans. Ind elec., vol.59, no.11, pp.4148-4154, Nov 2012. 